\title{
Gaya Komunikasi Pemilik Restoran Vegetus Vegetarian dalam Membangun Motivasi Kerja Karyawan
}

\author{
Evelyn, H.H. Daniel Tamburian \\ evelyn.915150010@stu.untar.ac.id,danielt@fikom.untar.ac.id
}

Fakultas Ilmu Komunikasi Universitas Tarumanagara

\begin{abstract}
One of many factors supporting someone's success in running a business is human resources, namely employees. In the restaurant business, employees play a very important role, because employees are serving consumers directly, while restaurant owners or leaders only provide guidance on how to serve consumers well. Therefore, each boss has a different communication style in building employees work motivation. This study aims to analyze the communication style of Vegetus Vegetarian Restaurant owner in building employees work motivation. This research is a qualitative descriptive study. This study uses the concept of communication style and motivation theory. Data collection in this study is carried out by interviewing Vegetus Vegetarian Restaurant owner and 3 employees who has worked for more than 3 years. In addition, author also conducts non-participant observation, literature review, and online data searching to obtain the data needed. The results of this study indicate that Vegetus Vegetarian Restaurant owner uses the equalitarian communication style and adheres to the theory of Maslow's hierarchy of needs in building employees work motivation. However, employees' needs are fulfilled randomly, so they do not depend on the order of needs in Maslow's hierarchy.
\end{abstract}

Keywords: Communication Style, Work Motivation, The Equalitarian Style

\begin{abstract}
Abstrak
Salah satu faktor penunjang keberhasilan seseorang dalam menjalankan sebuah bisnis adalah sumber daya manusia (SDM) yaitu karyawan. Dalam bisnis restoran, karyawan berperan sangat penting, karena karyawan melayani konsumen secara langsung. Sedangkan, pemilik restoran atau pimpinan hanya memberikan arahan bagaimana cara melayani konsumen dengan baik. Oleh karena itu, setiap atasan memiliki gaya komunikasi yang berbeda-beda dalam membangun motivasi kerja karyawan. Penelitian ini bertujuan untuk menganalisis gaya komunikasi pemilik Restoran Vegetus Vegetarian dalam membangun motivasi kerja karyawan. Penelitian ini merupakan penelitian deskriptif kualitatif. Penelitian ini menggunakan konsep gaya komunikasi dan teori motivasi. Pengumpulan data dalam penelitian ini dilakukan dengan cara wawancara dengan pemilik Restoran Vegetus Vegetarian dan tiga orang karyawan yang telah bekerja lebih dari tiga tahun. Selain itu, penulis juga melakukan observasi non-partisipan, studi pustaka, dan penelusuran data online untuk memperoleh data yang dibutuhkan. Hasil penelitian ini menunjukkan bahwa pemilik Restoran Vegetus Vegetarian menggunakan gaya komunikasi the equalitarian style dan menganut teori kebutuhan hierarki Maslow dalam membangun motivasi kerja karyawan. Namun, kebutuhan karyawan terpenuhi secara acak, jadi tidak bergantung pada urutan kebutuhan dalam hierarki Maslow.
\end{abstract}

Kata Kunci: Gaya Komunikasi, Motivasi Kerja, the equalitarian style 


\section{Pendahuluan}

Komunikasi merupakan bagian yang tidak dapat dipisahkan dalam kehidupan sehari-hari. Sebagai makhluk sosial, manusia tidak dapat hidup sendiri, ia membutuhkan dan memiliki kemampuan untuk berinteraksi dengan manusia lain. Menurut Carl Hovland, Janis dan Kelley (dalam Riswandi, 2009), komunikasi merupakan suatu proses di mana seorang komunikator menyampaikan stimulus (umumnya dalam bentuk kata-kata) untuk mengubah atau membentuk perilaku khalayak.

Salah satu faktor penunjang keberhasilan seseorang dalam menjalankan sebuah bisnis adalah sumber daya manusia (SDM), yaitu karyawan. Dalam bisnis restoran, karyawan berperan sangat penting, karena karyawanlah yang melayani konsumen secara langsung, sedangkan pemilik restoran atau pimpinan hanya memberikan arahan bagaimana cara melayani konsumen dengan baik. Menurut Tamburian (2013), keberhasilan komunikasi seorang pemimpin terletak pada komunikasi verbal dan komunikasi nonverbal. Apabila komunikasi antara kedua belah pihak sudah berjalan dengan baik, tentu akan menghasilkan output yang baik juga, karyawan akan senang melaksanakan perintah dari pemilik restoran dan tidak merasa terbebani.

Begitu pun sebaliknya, apabila pemilik restoran tidak berkomunikasi dengan baik dengan bawahannya, dapat dipastikan akan berpengaruh buruk terhadap kepuasan kerja karyawan. Karyawan yang telah kehilangan kepuasannya dalam bekerja akan berdampak pada menurunnya motivasi kerja di kemudian hari. Menurut Sukanto Reksohadiprodjo (dalam Masmuh, 2010), motivasi adalah suatu keadaan dalam diri seseorang yang mendorongnya untuk melakukan suatu kegiatan karena adanya tujuan yang ingin dicapai.

Maslow mengemukakan sebuah teori motivasi, yaitu teori hierarki kebutuhan. Maslow (dalam Pace dan Faules, 2010) mengemukakan bahwa kebutuhan kita terbagi menjadi lima kategori, yaitu kebutuhan fisiologis, kebutuhan akan keselamatan atau keamanan, rasa memiliki (belongingness) atau kebutuhan sosial, kebutuhan akan penghargaan, dan kebutuhan aktualisasi diri. Menurut Maslow, kebutuhan-kebutuhan ini berkembang dalam suatu urutan hierarkis di mana kebutuhan fisiologis merupakan kebutuhan yang paling dasar untuk tepenuhi. Kebutuhan ini mempunyai pengaruh atas kebutuhan-kebutuhan lainnya selama kebutuhan tersebut tidak terpenuhi. Contohnya, bukan berarti tidak mungkin, namun akan sulit bagi seseorang memikirkan investasi untuk masa depan di saat dirinya sedang merasa sangat kelaparan. Akan tetapi, kebutuhan pada tingkat yang lebih rendah tidak perlu terpenuhi secara lengkap sebelum kebutuhan berikutnya yang lebih tinggi menjadi aktif.

Susunan kebutuhan dalam tatanan hierarki Maslow, yaitu kebutuhan fisiologis berada pada tingkat paling bawah. Kebutuhan fisiologis antara lain gaji, uang makan, hari libur, dan uang transportasi. Kebutuhan selanjutnya di atas kebutuhan fisiologis, yaitu kebutuhan akan keselamatan dan keamanan, kebutuhan akan rasa memililki atau kebutuhan sosial, kebutuhan akan penghargaan, dan aktualisasi diri. Kebutuhan akan aktualisasi diri terletak pada tingkat paling atas. Begitu kebutuhan tubuh (fisiologis) terpenuhi orang akan berusaha untuk memenuhi kebutuhannya akan rasa aman dan keselamatan. Apabila kebutuhan akan keamanan dan keselamatan telah terpenuhi, ia akan berusaha untuk memenuhi kebutuhan selanjutnya, dan begitu pun seterusnya. Orang yang telah berhasil memenuhi kebutuhan-kebutuhan pada tingkat rendah, akan berusaha untuk memenuhi kebutuhan pada tingkat yang lebih tinggi. 
Evelyn, H.H. Daniel Tamburian: Gaya Komunikasi Pemilik Restoran Vegetus Vegetarian dalam Membangun Motivasi Kerja Karyawan

Untuk membangun motivasi kerja karyawan, setiap atasan atau pemilik restoran memiliki gaya komunikasi yang berbeda-beda. Steward L. Tubbs dan Sylvia Moss (dalam Ruliana, 2014) mendefinisikan gaya komunikasi sebagai seperangkat perilaku yang digunakan seseorang dalam situasi tertentu untuk memperoleh respons atau tanggapan dari orang lain. Gaya komunikasi yang digunakan tergantung pada maksud dari pengirim (sender) dan harapan dari penerima (receiver).

Steward L. Tubbs dan Sylvia Moss (dalam Ruliana, 2014) mengkategorikan gaya komunikasi dalam organisasi menjadi enam bagian. Yang pertama, yaitu the controlling style. Gaya komunikasi ini bersifat mengendalikan. Orang dengan gaya komunikasi the controlling style memiliki kehendak untuk mengatur dan membatasi perilaku dan tanggapan orang lain. Orang-orang yang menggunakan gaya komunikasi ini dikenal dengan sebutan komunikator.

Gaya komunikasi yang kedua adalah the equalitarian style. Gaya komunikasi ini memiliki aspek penting yang ditandai dengan adanya penyebaran pesan-pesan verbal yang bersifat dua arah (two-way traffic of communication), baik secara lisan maupun tertulis. Gaya komunikasi the equalitarian style sangatlah efektif dalam memelihara empati dan kerja sama dalam organisasi, terutama saat pengambilan keputusan. Selain itu, gaya komunikasi ini juga menjamin berlangsungnya tindakan sharing sesama anggota suatu organisasi.

Selanjutnya, ada gaya komunikasi the structuring style. Gaya komunikasi ini berfokus pada segala sesuatu yang terstruktur, seperti memantapkan perintah yang harus dilaksanakan, penjadwalan tugas dan pekerjaan serta struktur organisasi. Pengirim pesan (sender) mempengaruhi orang lain dengan cara berbagi informasi tentang tujuan organisasi, jadwal kerja, serta aturan dan prosedur yang berlaku dalam suatu organisasi.

Yang keempat, yaitu the dynamic style. Gaya komunikasi ini memiliki kecenderungan agresif dan berorientasi pada tindakan (action-oriented). Gaya komunikasi the dynamic style umumnya dipakai oleh juru kampanye ataupun supervisor yang membawahi salesmen atau saleswomen.

Gaya komunikasi yang kelima yaitu the relinguishing style. Orang dengan gaya komunikasi ini lebih mencerminkan pada kesediaan untuk menerima masukan maupun pendapat dari orang lain, daripada memberikan perintah, walaupun pengirim pesan (sender) berhak untuk memberikan perintah kepada orang lain. Pesan-pesan dalam gaya komunikasi ini akan efektif ketika pengirim pesan bekerja sama dengan orang-orang yang memiliki wawasan dan pengetahuan luas, teliti serta bertanggung jawab atas semua tugas atau pekerjaan yang diberikan kepadanya.

Dan gaya komunikasi yang terakhir adalah the withdrawal style. Orang yang menggunakan gaya komunikasi ini akan mengakibatkan melemahnya tindak komunikasi. Artinya, tidak ada keinginan dari orang-orang yang memakai gaya ini untuk berkomunikasi dengan orang lain, karena ada persoalan maupun kesulitan antarpribadi yang dihadapi oleh orang tersebut.

Perkembangan gaya hidup masyarakat yang begitu pesat dan daya konsumsi yang tinggi memicu persaingan antarprodusen untuk menjadikan produknya sebagai pemimpin pasar. Hal ini mendorong berdirinya banyak rumah makan atau restoran. Berdasarkan data dari Parama Indonesia, lembaga yang membantu perusahaan startup berkembang, sektor kuliner Indonesia tumbuh sekitar 7 hingga 14 persen per tahun dalam 5 tahun terakhir (https://www.cnnindonesia.com/gayahidup/20170118121405-262-187137/gaya-hidup-masyarakat-menjadikan-bisniskuliner-menjanjikan, diakses pada 5 September 2018 pukul 15.10 WIB). Pemilik 
restoran kemudian membangun restoran dengan karakteristik yang berbeda-beda sebagai diferensiasi dan keunggulan bagi restoran tersebut.

Restoran Vegetus Vegetarian merupakan salah satu restoran yang memiliki karakteristik yang cukup unik, karena restoran ini menyajikan makanan khusus vegetarian. Restoran vegetarian ini terletak di Jl. Pluit Karang Timur Blok O 8 No. 38-39, Pluit, Penjaringan, Jakarta Utara. Dalam jangka waktu dekat, Restoran Vegetus Vegetarian juga membuka cabang baru di daerah Serpong, Tangerang Selatan. Selain itu, Restoran Vegetus Vegetarian memiliki rating yang bagus di beberapa situs pencarian kuliner, diantaranya Zomato, Pergi Kuliner, Trip Advisor, dan Open Rice.

Kemampuan pemilik Restoran Vegetus Vegetarian dalam mempertahankan eksistensi restorannya di tengah persaingan bisnis yang begitu ketat menarik perhatian penulis untuk melakukan penelitian mengenai gaya komunikasi pemilik Restoran Vegetus Vegetarian dalam membangun motivasi kerja karyawan. Adapun tujuan dari penelitian ini adalah untuk mengetahui bagaimana gaya komunikasi pemilik Restoran Vegetus Vegetarian dalam membangun motivasi kerja karyawan.

\section{Metode Penelitian}

Dalam penelitian ini, penulis menggunakan pendekatan kualitatif. Menurut Herdiansyah (2014), penelitian kualitatif adalah suatu penelitian ilmiah yang bertujuan untuk memahami fenomena tertentu dengan mengutamakan proses interaksi komunikasi yang mendalam antara peneliti dengan fenomena yang diteliti. Penulis menggunakan metode pendekatan kualitatif sehingga dapat memahami dan memaparkan suatu fenomena dengan sejelas-jelasnya melalui pengumpulan data yang diperoleh dari proses interaksi komunikasi antara penulis dengan fenomena yang diteliti.

Penulis menggunakan metode penelitian deskriptif karena penulis ingin mengumpulkan data secara akurat dan sistematis, sehingga hasil penelitian ini dapat menggambarkan situasi yang terjadi di lapangan. Menurut Sugiyono (2011), metode deskriptif adalah metode yang digunakan untuk menggambarkan suatu hasil penelitian, tapi tidak digunakan untuk membuat kesimpulan yang lebih luas.

Untuk memperkuat data penelitian, maka penulis menggunakan metode pengumpulan data dengan melakukan wawancara, observasi non-partisipan, studi kepustakaan, dan penelusuran data online. Adapun narasumber dalam penelitian ini adalah pemilik Restoran Vegetus Vegetarian, yang bernama Teh Shintia (Ci Aping) dan 3 orang karyawan yang telah bekerja lebih dari 3 tahun.

Selain itu, penulis menggunakan teknik analisis data kualitatif dengan model interaktif. Miles dan Huberman (dalam Pujileksono, 2015) mengemukakan bahwa analisis data kualitatif terdiri dari tiga tahap, yaitu reduksi data, penyajian data, dan penarikan kesimpulan.

\section{Hasil Temuan dan Diskusi}

Berdasarkan wawancara penulis dengan pemilik Restoran Vegetus Vegetarian dan 3 orang karyawannya, penulis mendapatkan informasi-informasi berikut. Pemilik Restoran Vegetus Vegetarian yang bernama Teh Shintia atau kerap disapa Ci Aping lahir di Medan, pada tanggal 3 Maret 1976. Sebelum mendirikan Restoran Vegetus Vegetarian, Ci Aping pernah bekerja dengan bibinya dalam bidang usaha yang sama, 
Evelyn, H.H. Daniel Tamburian: Gaya Komunikasi Pemilik Restoran Vegetus Vegetarian dalam Membangun Motivasi Kerja Karyawan

yaitu kuliner. Keinginannya untuk menyajikan makanan yang sehat dengan harga terjangkau akhirnya mendorongnya untuk mendirikan restoran sendiri yang memiliki konsep makanan sehat (vegetarian, tidak mengandung daging) pada Januari 2011.

Ci Aping menggunakan bahasa Indonesia dan Mandarin untuk berkomunikasi sehari-hari dengan keluarganya. Namun, $\mathrm{Ci}$ Aping berkomunikasi dengan karyawannya hanya menggunakan bahasa Indonesia. $\mathrm{Ci}$ Aping cenderung menggunakan bahasa nonformal dengan karyawannya. Hal itu dikarenakan rata-rata karyawannya tidak bersekolah tinggi, jadi bahasa nonformal lebih memudahkan mereka untuk mengerti. Selain itu, dengan menggunakan bahasa nonformal, Ci Aping merasa lebih dekat dengan karyawannya.

Dalam menjalankan usaha restorannya, $\mathrm{Ci}$ Aping menerapkan sistem kekeluargaan. Ci Aping tidak membangun jarak dengan karyawan, ia tidak sungkan untuk turun tangan langsung membantu karyawannya melayani tamu saat restoran ramai. Baginya, karyawan sudah dianggap seperti keluarga sendiri. Selain itu, Ci Aping juga mau mendengarkan segala keluhan dan masukan dari karyawan agar karyawannya dapat bekerja secara maksimal sehingga Restoran Vegetus Vegetarian dapat lebih baik lagi ke depannya. Hal inilah yang membuat banyak karyawan betah bekerja di Restoran Vegetus Vegetarian.

Restoran Vegetus Vegetarian tidak memiliki manajer maupun supervisor. Oleh karena itu, Ci Aping biasanya menyuruh karyawan lain untuk menjelaskan tugastugas yang harus dilakukan kepada karyawan baru. Apabila masih belum mengerti, baru Ci Aping yang akan menjelaskannya lagi secara lebih detail. Ci Aping juga memantau sendiri pekerjaan karyawannya. Ia tidak ingin menjadi atasan yang dingin yang hanya memberikan gaji kepada karyawannya. Ci Aping ingin karyawannya merasa diperhatikan. Dengan memantau langsung pekerjaan karyawan, $\mathrm{Ci}$ Aping pun dapat membantu dan memberikan nasehat kepada karyawannya yang mengalami kesulitan.

Bagi Ci Aping sendiri kejujuran sangatlah penting. Ia selalu menanamkan sifat jujur pada karyawannya sejak awal mulai bekerja. Oleh karena itu, karyawannya tidak pernah mengambil uang penghasilan restoran maupun barang milik customer yang tertinggal. Apabila ada barang customer yang tertinggal di restoran, karyawannya pasti langsung memberikannya ke bagian kasir agar dapat diambil kembali oleh pemiliknya.

Selama menjalankan Restoran Vegetus Vegetarian selama kurang lebih 7 tahun, hanya ada 1 karyawan yang pernah mengambil uang tip di restoran. Awalnya, ia masih memaafkan dan hanya menegur karyawan tersebut, karena uang tip yang diambil tidak terlalu besar jumlahnya. Tapi, karena terus mengulangi kesalahan yang sama, maka Ci Aping pun memberikan tindakan tegas kepadanya. Ci Aping memecat karyawan tersebut karena mengabaikan teguran atasannya dan tidak dapat memperbaiki diri.

Untuk kesalahan-kesalahan yang dilakukan oleh karyawan, Ci Aping memberikan sanksi yang berbeda-beda. $\mathrm{Ci}$ Aping sudah sangat maklum untuk masalah pecahnya piring. Biasanya ia hanya memotong uang tip karyawan setiap bulannya. Sedangkan, untuk karyawan yang datang terlambat dan menumpahkan makanan atau minuman ke customer, Ci Aping akan menegur mereka, menanyakan kenapa hal tersebut bisa terjadi, dan memberikan nasehat atau solusi agar kejadian tersebut tidak terulang kembali.

Di antara semua kesalahan yang dilakukan karyawannya, bagi Ci Aping salah input orderan atau menyajikan makanan adalah kesalahan yang paling fatal. $\mathrm{Ci}$ 
Aping bahkan pernah memotong uang gaji mereka untuk menutupi kerugian yang ditanggung restoran. Namun karena merasa kasihan dan tidak tega, sekarang Ci Aping hanya menegur dan memberikan nasehat agar tidak melakukan kesalahan itu lagi. Setelah dinasehati, biasanya karyawan tidak akan salah lagi dalam menyajikan makanan, karena mereka akan memastikan kembali pesanan dari customer.

Menurut Romli (2014), faktor-faktor yang mempengaruhi motivasi terdiri atas faktor internal dan faktor eksternal yang berasal dari karyawan. Faktor internal yang dapat mempengaruhi pemberian motivasi pada seseorang, antara lain keinginan untuk dapat hidup, keinginan untuk dapat memiliki, keinginan untuk memperoleh pekerjaan, keinginan untuk memperoleh pengakuan, dan keinginan untuk berkuasa. Sedangkan, faktor eksternal yang dapat mempengaruhi motivasi seseorang dalam bekerja, yaitu kondisi lingkungan kerja, kompensasi yang memadai, supervisi yang baik, adanya jaminan pekerjaan, status dan tanggung jawab, serta peraturan yang fleksibel.

Ci Aping memanfaatkan faktor internal dan faktor eksternal untuk membangun motivasi kerja karyawan. Faktor internal yang dimaksud meliputi keinginan karyawan untuk bertahan hidup dan memiliki sesuatu. Selain memberikan gaji pokok kepada karyawan, Ci Aping juga membagikan uang tip yang dikumpulkan setiap 1 bulan sekali. Uang yang diperoleh karyawan, meliputi gaji dan uang tip, tentu bisa digunakan untuk bertahan hidup dan membeli kebutuhan mereka.

Sedangkan, faktor eksternal yang dimaksud meliputi kondisi lingkungan kerja yang menyenangkan dan peraturan yang fleksibel. Berdasarkan data yang diperoleh penulis, lingkungan kerja di Restoran Vegetarian Vegetus bisa dikatakan harmonis, karena tidak ada masalah antara satu karyawan dengan karyawan lainnya. Ci Aping sebagai atasan mereka juga menciptakan lingkungan kerja yang harmonis dengan menjalankan sistem kekeluargaan. $\mathrm{Ci}$ Aping terkadang mengajak karyawannya makan bersama di luar sebagai bentuk apresiasi kepada karyawannya karena telah bekerja dengan giat. Selain itu, peraturan di Restoran Vegetus Vegetarian juga fleksibel. Karyawan tidak segan untuk berkomunikasi langsung dengan $\mathrm{Ci}$ Aping selaku pemilik Restoran Vegetus Vegetarian, mulai dari menceritakan kesulitan yang dialami sampai meminta bantuan, walaupun tetap harus memperhatikan batasanbatasan tertentu.

Maya, Yani, dan Faris selaku karyawan yang bekerja di Restoran Vegetus Vegetarian pun merasa dihargai oleh Ci Aping sehingga mereka merasa nyaman dan betah bekerja di restoran itu. $\mathrm{Ci}$ Aping sendiri sebagai atasan tidak hanya memerintahkan karyawan untuk melayani customer, tapi juga mau turun tangan langsung membantu karyawan, bahkan membela karyawannya yang tidak bersalah di depan customer. Hal ini tentu dapat semakin memberikan motivasi kepada karyawan agar dapat bekerja secara maksimal dan membuat Restoran Vegetus Vegetarian lebih maju lagi ke depannya.

\section{Simpulan}

Setelah menganalisis data yang telah berhasil dikumpulkan, penulis menyimpulkan bahwa gaya komunikasi pemilik Restoran Vegetus Vegetarian dalam membangun motivasi kerja karyawan, yaitu the equalitarian style. Dalam menjalankan restorannya, Ci Aping menerapkan sistem kekeluargaan, tidak ada yang namanya atasan dan bawahan. Semuanya saling bekerja sama dalam melayani customer di Restoran Vegetus Vegetarian. Ci Aping pun tidak segan untuk turun 
tangan langsung membantu karyawannya apabila restoran sedang ramai. Selain itu, juga terdapat komunikasi yang bersifat dua arah (two-way traffic of communication). Ci Aping tidak hanya bersifat sebagai komunikator yang memberikan arahan dan perintah kepada karyawan, tapi karyawan pun juga dapat memberikan masukan dan menceritakan keluhan atau kesulitannya selama bekerja di Restoran Vegetus Vegetarian kepada Ci Aping. Gaya equalitarian style Ci Aping juga terlihat saat karyawannya melakukan kesalahan. Apabila karyawannya melakukan kesalahan, Ci Aping tidak memarahi, tapi hanya menegur mereka. $\mathrm{Ci}$ Aping menanyakan bagaimana kesalahan itu bisa terjadi serta memberikan masukan dan nasehat agar tidak mengulangi kesalahan itu kembali.

Dalam membangun motivasi kerja karyawan, Ci Aping menganut teori hierarki kebutuhan Maslow dengan memperhatikan faktor internal dan eksternal yang dapat mempengaruhi motivasi. Namun, kebutuhan karyawan terpenuhi secara acak, jadi tidak bergantung pada urutan kebutuhan dalam hierarki Maslow. Ci Aping dapat memenuhi kebutuhan karyawan pada tingkat 1 dan tingkat 3 dalam teori hierarki Maslow, yaitu kebutuhan fisiologis dan kebutuhan sosial. Kebutuhan fisiologis karyawan terpenuhi karena $\mathrm{Ci}$ Aping memberikan gaji pokok dan membagikan uang tips setiap bulannya. Sedangkan, kebutuhan sosial karyawan terpenuhi karena $\mathrm{Ci}$ Aping suka mengajak karyawannya untuk makan bersama di luar.

\section{Ucapan Terima Kasih}

Penulis memberikan ucapan terima kasih kepada Fakultas Ilmu Komunikasi Universitas Tarumanagara, pembimbing H.H. Daniel Tamburian, serta narasumber yaitu Teh Shintia (Ci Aping) selaku pemilik Restoran Vegetus Vegetarian dan tiga orang karyawan yang bersedia untuk diwawancara, yakni Maya, Yani, dan Faris. Penulis juga memberikan ucapan terima kasih kepada semua pihak yang telah mendukung dan membantu penelitian ini.

\section{Daftar Pustaka}

Gaya Hidup Masyarakat Menjadikan Bisnis Kuliner Menjanjikan. (2017, Januari 18). Retrieved September 5, 2018, from CNN Indonesia: https://www.cnnindonesia.com/gaya-hidup/20170118121405-262-

187137/gaya-hidup-masyarakat-menjadikan-bisnis-kuliner-menjanjikan

Herdiansyah, Haris. (2014). Metodologi Penelitian Kualitatif untuk Ilmu-Ilmu Sosial. Jakarta: Salemba Humanika

Masmuh, Abdullah. (2010). Komunikasi Organisasi dalam Perspektif Teori dan Praktek. Malang: UPT Penerbitan Universitas Muhammadiyah Malang

Pace, R. Wayne, \& Faules, Don F. (2010). Komunikasi Organisasi: Strategi Meningkatkan Kinerja Perusahaan. Bandung: PT Remaja Rosdakarya

Pujleksono, Sugeng. (2015). Metode Penelitian Komunikasi Kualitatif. Malang: Kelompok Intrans Publishing

Riswandi. (2009). Ilmu Komunikasi. Yogyakarta: Graha Ilmu

Romli, Khomsahrial. (2014). Komunikasi Organisasi Lengkap. Jakarta: PT Grasindo

Ruliana, Poppy. (2014). Komunikasi Organisasi: Teori dan Studi Kasus. Jakarta: PT Rajagrafindo Persada

Sugiyono. (2011). Metode Penelitian Pendidikan (Pendekatan Kuantitatif, Kualitatif dan $R \& D)$. Bandung: Alfabeta 
Vol. 2, No. 2, Desember 2018, Hal 329-336

Tamburian, H.H. Daniel. (2013). Gaya Komunikasi Jokowi Sebagai Pemimpin Indonesia. Jakarta: Ikatan Sarjana Komunikasi Indonesia 